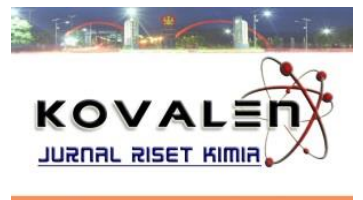

\title{
KAJIAN RETENSI KAROTEN KAPANG ONCOM MERAH DARI TONGKOL JAGUNG SELAMA PENGOLAHAN DAN PENYIMPANAN MIE INSTAN FUNGSIONAL
}

\section{STUDY OF ROTENTION CAROTEN MOLD RED ONCOM OF CORN COBS DURING PROCESSING AND STORAGE OF INSTANT NOODLES FUNCTION}

\author{
Nurakhirawati $^{\left.{ }^{*}\right)}$, Harianthy ${ }^{1)}$, Syaiful Bahri ${ }^{1)}$ \\ 1) Jurusan Kimia FMIPA Universitas Tadulako, Palu
}

Diterima 27 November 2015, Disetujui 28 Februari 2016

\begin{abstract}
Has done research on carotenoids retention oncom red on the processing and storage of instant noodles functional.This study aims was to determine the level of damage carotene in the instant noodle processing and to determine the carotene retention during storage of instant noodles as well as to determine the shelf life of instant noodles at a temperature $50^{\circ} \mathrm{C}$ and $60^{\circ} \mathrm{C}$. Estimation of shelf life or expiration period using the model of reaction kinetics the treatment phase of the study include red oncom mold production, processing instant noodles and storage of instant noodles on the temperature. Analysis carotene on instant noodlesdone every 0 days to 6 days using UV-Vis spectrophotometry method in wavelength. The data obtained is used to determine the shelf life of instant noodles. The results obtained showed live carotene demage during the processing of instant noodles is to $20 \mathrm{~g}=1,867 \%$. For temperature $60^{\circ} \mathrm{C}$ for $20 \mathrm{~g}=10,208 \%$, and determining Q10 is 2,90 and the expiration of a functional instant noodles is 122 days.
\end{abstract}

Keywords : Carotene, Mie Functional, Retention carotene, Shelf life, Reaction Kinetics Model

\begin{abstract}
ABSTRAK
Telah dilakukan penelitian tentang retensi karoten kapang oncom merah (Neurospora sp.) pada mie instan fungsional selama proses pengolahan dan penyimpanan. Tujuannya adalah untuk mengetahui tingkat kerusakan karoten pada pengolahan mie instan dan untuk mengetahui retensi karoten selama penyimpanan mie instan serta untuk mengetahui masa kadaluarsa mie instan pada suhu $50{ }^{\circ} \mathrm{C}$ dan 60 ${ }^{\circ} \mathrm{C}$. Pendugaan umur simpan atau masa kadaluarsa menggunakan model kinetika reaksi. Perlakuan penelitian meliputi tahap produksi kapang oncom merah, pengolahan mie instan, dan penyimpanan mie instan pada suhu $50{ }^{\circ} \mathrm{C}$ dan $60{ }^{\circ} \mathrm{C}$. Analisis karoten pada mie instan dilakukan pada hari ke 0,1 , 2, 3, 4, 5, dan 6 menggunakan metode spektrofotometri UV-Vis pada panjang gelombang $470 \mathrm{~nm}$. Hasil yang diperoleh menunjukkan tingkat kerusakan karoten selama pengolahan mie instan pada suhu $50^{\circ} \mathrm{C}=1,867 \%$, suhu $60^{\circ} \mathrm{C}=10,208 \%$, dan penentuan Q10 adalah 2,90 serta masa kadaluarsa mie instan fungsional adalah 122 hari pada suhu $50^{\circ} \mathrm{C}$, dan 42 hari pada suhu $60^{\circ} \mathrm{C}$.
\end{abstract}

Kata kunci: Karoten, Mie fungsional, Retensi karoten, Umur simpan, Model kinetika reaksi 


\section{LATAR BELAKANG}

Perkembangan ilmu pengetahuan dan teknologi yang semakin meningkat menyebabkan keinginan manusia semakin meningkat pula. Seiring dengan meningkatnya kebutuhan manusia akan pangan menuntut segala sesuatu yang serba cepat. Dalam hal makanan, masyarakat cenderung lebih menyukai produk pangan yang berbentuk instan (Hendy, 2007).

Mie merupakan produk pangan instan yang banyak dijadikan sebagai makanan untuk sarapan maupun sebagai makanan selingan. Tingkat konsumsi mie instan masyarakat Indonesia cukup tinggi, yakni sebesar 75 bungkus per kepala per tahun (Badilangoe, 2012). Produk - produk mie saat ini telah mengalami perkembangan dengan variasi campuran antara terigu sebagai bahan baku utama dengan bahan - bahan lain seperti umbi -umbian, kacang kacangan dan sayur - sayuran yang tentu saja dapat meningkatkan kandungan gizi mie tersebut. Makanan tersebut banyak diminati konsumen, tidak hanya memiliki komposisi gizi yang baik, serta penampakan dan cita rasa yang menarik, akan tetapi juga mempunyai fungsi fisiologis tertentu bagi tubuh (Badilangoe, 2012).

Industri pangan telah banyak menghasilkan berbagai inovasi produk makanan yang kurang aman dan kurang layak untuk dikonsumsi, misalnya makanan tersebut mengandung bahan pengawet, pemanis ataupun bahan tambahan lain yang berbahaya bagi kesehatan manusia. Karena itu, untuk memperoleh makanan yang memiliki nilai positif bagi kesehatan perlu dilakukan dengan cara pengolahan yang baik melalui proses tertentu. Salah satunya adalah menggunakan zat antioksidan alami,

Makanan instan yang dapat dijadikan sebagai makanan fungsional yakni makanan yang mengandung satu atau lebih senyawa yang memiliki fungsi fisiologis dan bermanfaat bagi tubuh, terutama bagi anak - anak prasekolah dan dewasa oleh karena itu, perlu ada kajian kearah tersebut (Syamsir, 2012).

Oncom merupakan salah satu produk fermentasi makanan khas Jawa yang menggunakan substrat bungkil kacang tanah atau ampas tahu yang diinokulasi dengan spora kapang oncom merah, yaitu spesies kapang yang berkembang biak secara generatif. Menurut Saosono et. al. (1986) dalam Indarto (2010), fermentasi oncom merah melibatkan kapang Neurospora $s p$, yaitu kapang yang mudah tumbuh pada substrat dan miseliumnya terdiri dari hifa yang bercabang, menjulang ke udara, yang mudah dikenal dari konidianya yang berwarna jingga. Neurospora crassa memproduksi pigmen karotenoid secara intraseluler yang tersimpan dalam konidia yang menyebabkan terbentuknya warna jingga. Mappiratu (1990) menggunakan bahan karotenoid yang diproduksi Neurospora crassa didominasi oleh beta karoten, diatas $50 \%$ dari total karotenoid yang ada. 
Karotenoid termasuk salah satu pigmen alami yang besar peranannya dalam industri pengolahan pangan, terutama karoten.

\section{METODE PENELITIAN}

\section{Bahan dan Peralatan}

Bahan-bahan yang digunakan adalah tongkol jagung manis muda, tepung terigu, telur ayam, baking powder, air, garam, kapang oncom merah, bahan lain sebagai bahan pengekstrak dan bahan kimia untuk analisis mencakup n-heksan teknis, aseton teknis, natrium sulfat anhidrat $\left(\mathrm{Na}_{2} \mathrm{SO}_{4}\right)$, akuades, aluminium foil, dan kertas saring.

Alat yang digunakan adalah talang, baskom, kompor, panci pengukus, neraca analitik, mesin penggiling mie (Rollpress), sendok pengaduk, Oven, blender, shaker, spektrofometer UV-Visibel, kuas, Talang aluminium, alat pengering surya dan alat alat gelas yang digunakan dalam laboratorium.

\section{Prosedur Penelitian}

\section{Produksi karoten kapang oncom merah}

Produksi karoten dilakukan secara fermentasi menggunakan medium tongkol jagung manis muda. Pelaksanaan mengikuti cara Mappiratu (1990) sebagai berikut: tongkol jagung manis muda yang diperoleh dari pasar Masomba Palu, disortir kemudian disterilkan dengan cara dikukus selama 1 jam. Tongkol jagung disortir kemudian disterilkan dengan cara dikukus selama 1 jam. Tongkol jagung yang telah dikukus dibiarkan atau disimpan diatas rak besi. Untuk menjaga kelembaban, rak ditutup dengan plastik dan dibiarkan selama 5 hari. Konidia kapang oncom merah kuning kemerahmerahan yang tumbuh pada tongkol jagung dipisahkan dengan memakai kuas. karoten, diawetkan dengan cara merendam oncom merah dalam larutan etanol $96 \%$ dan didiamkan selama \pm 4 hari, kemudian disaring dan dikeringkan menggunakan corong bucner. Oncom merah yg sudah diawetkan, siap digunakan untuk ditambahkan kedalam adonan mie instan fungsional.

\section{Analisis Karoten}

Analisis karoten oncom merah dilakukan menggunakan metode spektrofotometri (Mappiratu, 1990) sebagai berikut: sampel dalam adonan di ekstrak dengan campuran pelarut heksan : aseton ( $1: 2 \mathrm{v} / \mathrm{v}$ ) beberapa kali diatas mesin kocok agitasi $250 \mathrm{rpm}$ hingga semua karoten terekstrak (ekstraknya tidak lagi berwarna). Ekstrak karoten yang dihasilkan di lewatkan pada natrium sulfat anhidrat untuk membebaskan air yang terikat. Ekstrak karoten selanjutnya di analisis kandungan karotennya dengan menggunakan spektrofotometri uv-vis. Kadar karoten dapat di hitung dengan menggunakan persamaan:

$$
x=\frac{A \cdot Y}{E_{1 \mathrm{~cm}}^{1 \%} \cdot 100}
$$

Dimana :

$$
\begin{aligned}
X & =\text { Berat karoten }(\mathrm{g}) \\
\mathrm{A} & =\text { Absorban } \\
\mathrm{Y} & =\text { Jumlah Volume ekstrak karoten }(\mathrm{mL}) \\
E_{1 \mathrm{~cm}}^{1 \%} & =\text { Koefisien ekstingsi molar }(2500)(\mathrm{mL} / \mathrm{g})
\end{aligned}
$$


Penentuan waktu simpan karoten kapang oncom merah, Data yang dihasilkan digunakan untuk menentukan waktu simpan pada suhu. Data waktu simpan tersebut digunakan untuk menentukan nilai $Q_{10}$, dan data nilai $Q_{10}$ digunakan untuk menetukan waktu simpan pada berbagai suhu. Penentuan waktu simpan menggunakan persamaan regresi linier orde $1(y=a x+b)$, nilai $Q_{10}$ dihitung menggunakan persamaan:

$$
Q_{10}=\frac{\text { Waktu simpan Suhu } 50^{0}}{\text { waktu simpan suhu } 60^{0}}
$$

\section{Pembuatan Mie Instan Fungsional}

Pembuatan mie karoten kapang oncom merah dilakukan dengan cara menambahkan oncom merah yang mengandung karoten dengan variasi sebanyak $20 \mathrm{~g}$ oncom merah ke dalam tepung terigu sebanyak $150 \mathrm{~g}$ dicampur dengan $25 \mathrm{~g}$ butir telur ayam, $5 \mathrm{~g}$ garam, $1,5 \mathrm{~g}$ baking powder, dan $15 \mathrm{ml}$ air, kemudian diaduk hingga membentuk adonan yang khalis. Adonan selanjutnya dicetak menggunakan roll-press membentuk lembaran-lembaran mie. Lembaran mie kemudian dikukus selama \pm 5 menit. Kemudian dikeringkan menggunakan alat pengering surya hingga kering. Mie instan yang dihasilkan dikemas dan disimpan selama 0 - 6 hari dan dianalisis karotennya setiap 24 jam. Jika proses pengeringan dilakukan dengan udara panas, maka digunakan suhu 70 $90 \stackrel{\circ}{ }{ }^{\circ}$ selama 30 - 40 menit.

Mencuci dengan bersih cawan petri yang hendak digunakan kemudian dimasukkan ke dalam oven bersuhu $105^{\circ} \mathrm{C}$ selama 1 jam. Selanjutnya cawan petri yang telah dipanaskan dikeluarkan dari oven dengan tang/gegep dan dimasukkan ke dalam desikator sekitar 30 menit (agak dingin). Cawan petri yang telah dipanaskan tersebut ditimbang dengan neraca analitik dan dinyatakan beratnya sebagai berat cawan petri kosong (WI), kemudian diisi dengan adonan mie dan mie instan yang ingin ditetapkan kadar airnya. Cawan petri yang telah terisi dengan bahan selanjutnya ditimbang kembali dengan neraca analitik dan dicatat beratnya (W2). Cawan petri dimasukkan kembali ke dalam oven yang bersuhu sama dengan cawan petri kosong, kemudian dipanaskan hingga beratnya konstan (pemanasan berlangsung sekitar 3 jam) dan dicatat beratnya (W3). Kadar air bahan dihitung menggunakan rumus:

$$
\text { Kadar air bahan }=\frac{\mathrm{W} 2-\mathrm{W} 3}{\mathrm{~W} 2-\mathrm{W} 1} \times 100 \%
$$

$$
\begin{aligned}
\text { Dimana }: & \text { W1 } \\
\text { W2 } & =\text { berat cawan kerat cawan }+ \text { bahan } \\
\text { W3 } & =\text { berat konstan }
\end{aligned}
$$

Penentuan waktu simpan karoten kapang oncom merah, Data yang dihasilkan digunakan untuk menentukan waktu simpan pada suhu. Data waktu simpan tersebut digunakan untuk menentukan nilai $Q_{10}$, dan data nilai $Q_{10}$ digunakan untuk menetukan waktu simpan pada berbagai suhu. Penentuan waktu simpan menggunakan persamaan regresi linier orde $1(y=a x+b)$, nilai $Q_{10}$ dihitung menggunakan persamaan:

$$
\mathrm{Q}_{10}=\frac{\text { Waktu simpan Suhu } 50^{0}}{\text { waktu simpan suhu } 60^{0}}
$$




\section{Penentuan Retensi Karoten}

Retensi karoten ditentukan menggunakan persamaan berikut:

Retensi Karoten $=\frac{\text { kadar karoten mie instan }}{\text { kadar karoten adonan mie }} \times 100$

\section{HASIL DAN PEMBAHASAN}

\section{Tahap Produksi Kapang Oncom Merah}

Tahap produksi karoten diawali dari proses fermentasi oncom merah. Pada hari pertama inkubasi tampak benang-benang halus pada permukaan tongkol jagung. Benang-benang halus itu disebut hifa. Pemindahan mikroba dari suatu medium ke medium lain, menyebabkan mikoroba akan mengalami fase adaptasi unutk melakukan penyesuaian dengan substrat dan lingkungan alam sekitar. Pada fase ini, belum terjadi pembelahan sel karena beberapa enzim mungkin belum disintesis. Setelah hari kedua inkubasi, kapang mulai tumbuh pada permukaan tongkol jagung yang ditandai dengan terbentuknya benang-benang yang berwarna orange. Neurospora dicirikan dengan adanya bentuk semacam rantai yang merupakan deretan spora berwarna terang dan berasal dari konidia yang tidak terlihat.

Pertumbuhan mikrobial ditandai dengan peningkatan jumlah dan massa sel. Pada hari pertama ini, pertumbuhan kapang baru berada pada fase adaptasi. Setelah mengalami fase adaptasi, sel mulai membelah dengan kecepatan yang masih rendah karena baru tahap penyesuaian diri. Hasil pengamatan pada hari keenam inkubasi terdapat banyak masa sel. Menurut Widjoyo (2008), Sebagian populasi mulai mengalami kematian yang disebabkan oleh nutrisi yang ada pada media dan energi cadangan di dalam sel sudah habis. Pada hari keenam inkubasi, sebagian kapang diduga sudah pada fase kematian, hal ini ditunjukan terjadi perubahan pada benang- benang miselium berubah warnanya menjadi kehitaman dan sporanya telah berkurang secara siknifikan.

\section{Kadar Karoten Dari Kapang Oncom Merah dan Mie Instan}

Analisis karoten dimulai dari kapang oncom merah, dilakukan dengan cara penambahan pelarut organik untuk melarutkan karoten dari bahan tersebut, seperti yang terdapat pada mie instan. Pelarut yang digunakan adalah campuran pelarut aseton dan $\mathrm{n}$-heksan $(2: 1 \mathrm{v} / \mathrm{v})$. Selain berfungsi sebagai pelarut, pemilihan pelarut ini, juga tidak begitu toksis sehingga aman digunakan dalam ekstraksi.

Pada perlakuan ini, dalam ekstraksi karoten menggunakan pelarut aseton dan n-heksan diperoleh larutan yang berwarna kuning yang merupakan warna khas untuk senyawa karoten. Karena larutan karoten berwarna kuning, sehingga dapat dianalisis secara spektrofotometri. Analisis spektrofotometri ini, sebelumnya dilakukan dengan mencari panjang gelombang maksimum dari panjang gelombang 400 500 nm. Berdasarkan uji identifikasi diperoleh panjang gelombang maksimum $470 \mathrm{~nm}$. 
Menurut Brintton (1995) hampir semua spektrum karotenoid terletak pada panjang gelombang maksimum antara 400 $500 \mathrm{~nm}$. Pada penelitian ini, identifikasi karoten dari kapang oncom merah menggunakan panjang gelombang maksimum yakni $470 \mathrm{~nm}$.

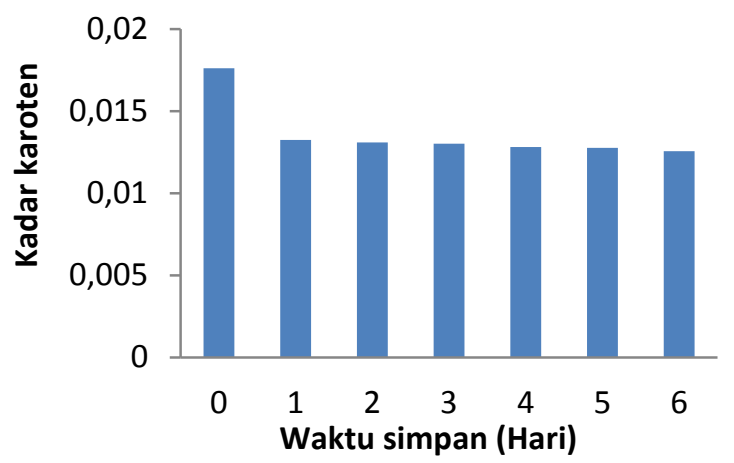

Gambar 1.Kadar karoten mie instan fungsional pada waktu penyimpanan suhu $50^{\circ} \mathrm{C}$ sebanyak $20 \mathrm{~g}$ oncom merah

Tabel 1. Kadar air Adonan mie dan Mie instan

\begin{tabular}{ccc}
\hline $\begin{array}{c}\text { Kadar Karoten } \\
\text { dalam Adonan dan } \\
\text { Mie }(\mathrm{g})\end{array}$ & $\begin{array}{c}\text { Kadar Air } \\
\text { Adonan } \\
(\%)\end{array}$ & $\begin{array}{c}\text { Kadar } \\
\text { Air Mie } \\
(\%)\end{array}$ \\
\hline 20 & 12,629 & 6,32 \\
\hline
\end{tabular}

\section{Kadar Air Adonan dan Mie Instan}

Air merupakan komponen penting dalam bahan makanan karena air dapat mempengaruhi, tekstur serta cita rasa makanan (Respati, 2010). Dalam pembuatan mie instan fungsional yang dilakukan menggunakan telur dan air, di mana air berfungsi sebagai media reaksi antara gluten dan karbohidrat, melarutkan garam, dan memberikan sifat kenyal gluten (Prangdimurti,1991).
Menurut Sunaryo (1985), air yang ditambahkan umumnya berjumlah 28-38\% dari berat tepung. Jika penambahan air lebih dari 38\%, adonan akan menjadi basah dan lengket. Bila penambahan air kurang dari $28 \%$ menyebabkan adonan menjadi keras, rapuh dan sulit untuk dibentuk menjadi lembaran (Astawan, 2008). Untuk membuat adonan yang baik faktor yang harus diperhatikan adalah jumlah air yang ditambahkan, dalam pencampuran jumlah air yang digunakan adalah $15 \mathrm{ml}$ dan waktu pengadukan \pm 5 menit.

\section{Waktu Masak Mie Instan yang Dihasilkan \\ Salah satu parameter penting dari} produk instan adalah waktu rehidrasi. Waktu rehidrasi merupakan waktu yang dibutuhkan mie untuk kembali mengabsorpsi air sehingga teksturnya menjadi kenyal dan elastis seperti sebelum dikeringkan. Penentuan waktu optimum rehidrasi dilakukan dengan memasak mie dalam air mendidih, lalu menghitung waktu yang dibutuhkan sampai mie benar-benar matang dan siap untuk dikonsumsi, tetapi menjaga jangan sampai mie terlalu matang.

Penentuan waktu optimum rehidrasi ini penting dilakukan untuk menghasilkan tekstur mie matang yang diinginkan. Jika mie dimasak terlalu matang (overcooked), maka mie dapat menjadi lengket dan mudah hancur. Sebaliknya jika mie belum matang benar, bagian tengah mie masih 
terasa keras saat dikunyah. Waktu masak mie instan fungsional dari hasil penelitian adalah 5 menit. Menurut Wibowo (2008) dalam Isnaini (2013), lamanya waktu rehdrasi disebabkan permukaan mie keras dan padat, sehingga air akan sulit untuk masuk kebagian dalam mie saat rehidrasi.

\section{Kerusakan Karoten Selama Pengolahan Mie Instan}

Karoten akan rusak selama proses pengeringan dan pengukusan,makin tinggi suhu dan makin lama waktu pemanasan yang diberikan maka akan semakin banyak karoten yang rusak karena mudah teroksidasi. Karotenoid merupakan senyawa alami yang tingkat ketidakjenuhannya sangat tinggi sehingga mudah terdegradasi akibat oksidasi dan proses pemanasan. faktor yang mengakibatkan terdegradasinya karoten, sebab karoten tersebut mudah rusak akibat pengaruh dari lingkungan sekitar. Beberapa faktor yang mempengaruhi adalah adanya oksigen dan cahaya selama waktu proses dan penyimpanan produk. Menurut Harris dan Karnas (1989) bahwa karoten lebih baik disimpan dalam lingkungan lembab, tetapi dengan cepat kehilangan aktifitasnya apabila dipanaskan dalam lingkungan beroksigen, terutama pada suhu tinggi.

Pemanasan yang lama pada suhu $180^{\circ} \mathrm{C}$ (pada kondisi tanpa oksigen) hanya menyebabkan sedikit kerusakan pada molekul ini, namun pada bahan pangan (dengan adanya komponen penyusun berupa pati, lemak, dan lain-lain) serta dikombinasikan dengan pencampuran serta mekanis akan memberi kesempatan masuknya $\mathrm{O}_{2}$ dan menyebabkan kerusakan molekul karoten ini lebih besar hingga jauh lebih besar lagi.

Pemanasan pada suhu yang tidak terlalu tinggi dalam waktu singkat dapat menyebabkan isomerisasi beberapa ikatan trans menjadi cis dan penurunan kadar karoten yang menyebabkan terjadinya proses oksidasi Kurniawan (2012) dalam Ranonto (2015). Hasil penelitian ini, tingkat kerusakan dari karoten yakni hari ke-0 untuk suhu $50^{\circ} \mathrm{C}$ untuk $20 \mathrm{~g}=1,867 \%$ dan untuk suhu $60^{\circ} \mathrm{C} 20 \mathrm{~g}=10,208 \%$.

\section{Waktu Simpan Karoten Pada Suhu $50^{\circ} \mathrm{C}$ dan $60^{\circ} \mathrm{C}$}

Harris dan Karnas

menyatakan bahwa senyawa karoten akan mengalami degradasi atau mengalami kerusakan yang nyata pada pemanasan di atas $80^{\circ} \mathrm{C}$, baik dengan pengukusan, perebusan, maupun penggorengan dengan tingkat kerusakan hingga 40-50\%. Mutu pangan dan produk olahan akan mengalami perubahan selama penyimpanan, yang pada saat tertentu mutunya tidak lagi dapat diterima. Jangka waktu yang menyebabkan mutu pangan atau produk olahan tidak lagi dapat diterima disebut sebagi jangka waktu kadaluarsa atau umur simpan (shelf life) bahan pangan maupun produk olahannya (Mappiratu, 2012). Untuk produk karoten, waktu simpannya adalah waktu dimana retensi karoten mencapai 30\%. 


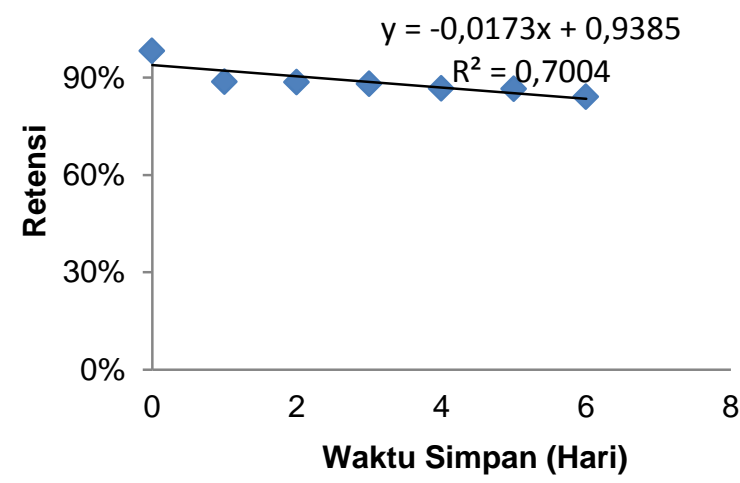

Gambar 2. Kurva hubungan antara retensi karoten terhadap waktu simpan mie instan pada suhu $60^{\circ} \mathrm{C}$ (orde reaksi nol)

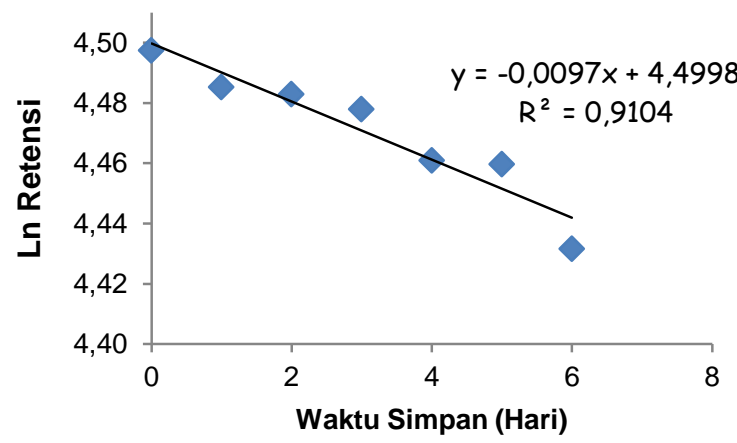

Gambar 3. Kurva hubungan antara In retensi karoten terhadap waktu simpan mie instan pada suhu $50^{\circ} \mathrm{C}$ (orde reaksi satu)

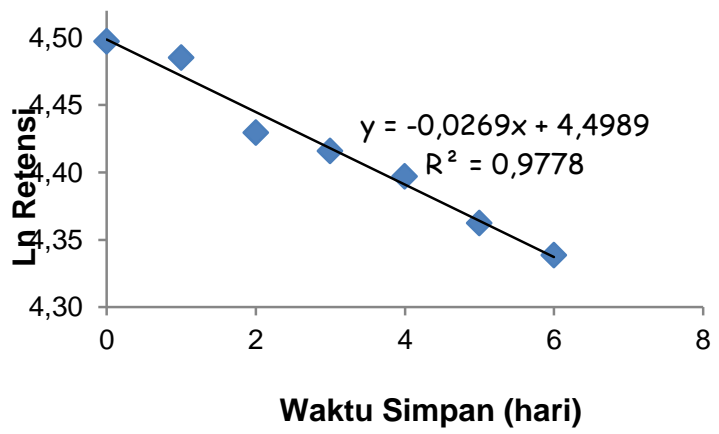

Gambar 4. Kurva hubungan antara In retensikaroten terhadap waktu simpan mie instan pada suhu $60^{\circ} \mathrm{C}$ (orde reaksi satu)
Umur Simpan Karoten dari Kapang Oncom Merah dalam Mie Pada Berbagai Suhu Penyimpanan

Digunakan persamaan berikut (Koswara, 2002 dalam Sary, 2011).

$$
Q_{10}{ }^{(\delta / 10)}=\frac{\text { ts }(T)}{\text { ts }(T+10)}
$$

Berdasrkan persamaan tersebut, maka umur simpan produk karoten dalam mie instan pada berbagai suhu disajikan pada Tabel 2.

Tabel 2. Umur simpan karoten mie instan

\begin{tabular}{ccc}
\hline No. & $\begin{array}{c}\text { Suhu } \\
\text { penyimpanan } \\
\left({ }^{\circ} \mathrm{C}\right)\end{array}$ & $\begin{array}{c}\text { Umur simpan } \\
\text { produk karoten } \\
\text { (hari) }\end{array}$ \\
\hline 1 & 15 & 5058,71 \\
2 & 20 & 2970,58 \\
3 & 25 & 1744,38 \\
4 & 30 & 1024,33 \\
5 & 35 & 601,51 \\
6 & 40 & 353,22 \\
7 & 45 & 207,41 \\
8 & 50 & 121,80 \\
9 & 55 & 71,52 \\
10 & 60 & 42,00 \\
\hline
\end{tabular}

\section{KESIMPULAN}

Berdasarkan hasil penelitian, dapat disimpulkan: retensi karoten mie instan fungsional suhu $50^{\circ} \mathrm{C}$ untuk $20 \mathrm{~g}=1,867$. Selanjutnya pada suhu $60^{\circ} \mathrm{C}$ untuk $20 \mathrm{~g}=$ $10,208 \%$, dan Masa simpan mie instan fungsional yang disimpan pada suhu $50^{\circ} \mathrm{C}$ adalah 122 hari dan pada suhu $60^{\circ} \mathrm{C}$ adalah 42 hari. Selanjutnya disarankan untuk menggunakan mikroba yang ditumbuhkan pada tongkol jagung sehingga diperoleh beta karoten yang lebih banyak. 


\section{DAFTAR PUSTAKA}

Astawan M. 2006. Membuat Mie dan Bihun. Jurnal Pangan dan Agroindustri. 2 (4) : 101-112.

Brintton J., Pfander. $1995 . \quad$ Kendali Stabilitas Beta Karoten Selama Proses Produksi Tepung Ubi Jalar. [Skripsi], Bogor: Institut Pertanian Bogor.

Harris R.S., Karnas E. 1989. Evaluasi Gizi pada Pengolahan Bahan Pangan. Bandung: ITB.

Hendy. 2007. Formulasi Bubur Instan Berbasis Singkong (Manihot esculenta Crantz) sebagai Pangan Pokok Alternatif. Jurnal Pangan. 2 (3): 1- 14.

Indarto AD. 2010. Pengaruh Waktu Inkubasi Terhadap Kandungan Karoten Dari Kapang Oncom Merah. [Skripsi]. Palu: Universitas Tadulako.

Isnaini RF. 2013. Pembuatan Mie Instan Berbahan Tepung Jagung Lokal Riau dan Tapioka. Jurnal online Mahasiswa (JOM) Bidang Pertanian. 1(1): 1-9.

Mappiratu, 1990. Produksi $\beta$-Karoten pada Limbah Cair Tapioka dengan Kapang Oncom Merah. [Tesis]. Bogor: FPSIPB, Bogor.

Mappiratu. 2012. Teknologi Pangan. Palu: Tadulako University Press.

Prangdimurti E. 1991. Fortifikasi Zat Besi pada Mie Kering yang Dibuat dari Campuran Tepung Terigu dan Tepung Singkong. [Skripsi]. Bogor: Fakultas Teknologi Pertanian Institut Pertanian Bogor.

Ranonto S. 2015. Retensi Karoten Dalam Berbagai Produk Olahan Labu kuning (Curcubita moschata Durch). Online Jurnal Of Natural Science. 4(1):104110.

Respati AN. 2010. Pengaruh Penggunaan Pasta Labu Kuning (Curcubita moschata) untuk Substitusi Tepung Terigu dengan Penambahan Tepung Angkak dalam Pembuatan Mie Kering. [Skripsi]. Surakarta: Fakultas Pertanian Universitas Sebelas Maret Surakarta.

Sary MA. 2011, Penerapan Model Kinetika Reaksi untuk Menduga Umur Simpan Likopen dari Buah Semangka
(Citrullus vulgaaris Schard) dalam Kemasan Kapsul. [Skripsi]. Palu: Program Studi Kimia FMIPA Universitas Tadulako.

Sunaryo E. 1985. Formulasi Mie Kering dengan Subtitusi Tepung Kimpul. Jurnal Pangan dan Agroindustri. 2(4): 101-112.

Syamsir E. 2012. Pangan Fungsional dari Pangan Tradisional. (http://ilmu panagan. Blogspot.com/p/blogpersonal-tentang pangan.html, diakses pada tanggal 3 september 2014).

Widjoyo S. 2008. Nutrisi Lingkungan dan kondisi Jasat Renik. Jakarta: Pustaka Buku.

Badilangoe PM. 2012. Kualitas Mi Basah dengan Penambahan Ekstrak Wortel (Daucus Carota L.) dan Subtitusi Tepung Bekatul. [Skripsi]. Yogyakarta: UAJY. 